Cuadernos de Filología Clásica. Estudios Latinos

ISSN: 1131-9062

https://dx.doi.org/10.5209/cfcl.64895

\title{
Adiós a Barataria: Horacio y el Quijote, 2.53 (y 2.58) ${ }^{1}$
}

Daniel López-Cañete Quiles²

Recibido: 21/03/2019 / Aceptado: 16/06/2019

Resumen. Análisis de influencias horacianas, con especial atención a Epist.1.7, en el discurso de renuncia de Sancho Panza como gobernador de Barataria (2.53) y en el de D. Quijote sobre la libertad (2.58).

Palabras clave: Quijote; Horacio; Sátiras y Epístolas; campo vs. ciudad

[en] Goodbye to Barataria: Horacio and the Quijote, 2.53 (and 2.58)

\begin{abstract}
This article explores Horatian influences (especially from Epist.1.7) on Sancho Panza's speech of resignation as governor of Barataria (2.53) as well as on D. Quijote's speech on freedom (2.58).
\end{abstract}

Keywords: D. Quijote; Horace; Satires and Epistles; country vs. town.

Cómo citar: López-Cañete Quiles, D., «Adiós a Barataria: Horacio y el Quijote, 2.53 (y 2.58)», en Cuad. Filol. Clás. Estud. Lat. 39.1 (2019), 111-127

El pasaje en castellano que primordialmente nos interesa corresponde al «fatigado fin y remate que tuvo el gobierno de Sancho» en la Ínsula Barataria, asunto del capítulo 53 de la Segunda Parte del Quijote 3 . En los capítulos anteriores hemos visto al escudero, ya encumbrado a gobernador de la fingida república, mostrar un sorprendente buen criterio y sabiduría al administrar justicia y «hacer estatutos y pragmáticas», pero en la hora del peligro su energía y su valor quedaron muy en entredicho: unos supuestos «infinitos enemigos» habrían emprendido un «asalto furioso» contra la Ínsula y, mientras Barataria era, no menos supuestamente, defendida por sus súbditos con profusión de ardor guerrero, un aterrado Sancho cayó trabado por los dos paveses que le habían puesto por

1 Leyeron y mejoraron el borrador con valiosísimas sugerencias mis maestros Juan Gil, José María Maestre, así como Isabel Román, Bartolomé Pozuelo, Ana Pérez Vega, José Armenta y Mercedes Comellas; mi profunda gratitud a todos ellos.

2 Universidad de Sevilla, Facultad de Filología. Departamento de Filología Griega y Latina.

3 El texto del Quijote seguido es el de Rico (2015, I 1163-1164). La abreviatura empleada en la misma edición para el título de la novela $(D Q)$ aparecerá aquí sólo cuando el contexto comprometa la claridad de la referencia a este título; de lo contrario, me limitaré a indicar la Primera o Segunda parte y el número de capítulo (en ambos casos con cifras arábigas), seguidos del número de página correspondiente al primer volumen de Rico 2015. Por el contrario, las citas del 'Volumen complementario' de este trabajo incluirán el nombre del autor, el año y el número romano del volumen (II), seguido del de página; igual ocurrirá con el primer volumen, que contiene texto de la novela, en caso de referencia a una nota infrapaginal. Salvo mención expresa en otro sentido, las ediciones de los demás textos hispánicos citados - de Cervantes inclusive- son las del CORDE, al que remito para la referencia de editor, fecha y página, datos aquí sacrificados a la brevedad. 
armadura, quedando inmóvil en el suelo «como galápago, encerrado y cubierto con sus conchas, o como medio tocino metido entre dos artesas». Pasado el peligro, «limpiaron» a nuestro héroe ${ }^{4}$, que exhausto de la tensión se desmayó sobre su lecho y, tras volver en sí, se vistió en silencio ante «los de la burla» y marchó a la caballeriza, donde abrazó a su rucio entre lágrimas y suspiros de añoranza por la vida simple pero dichosa que había disfrutado en compañía del animal, y que en mala hora despreciara cuando «me subí sobre las torres de la ambición y de la soberbia», donde «se me han entrado por el alma adentro mil miserias, mil trabajos y cuatro mil desasosiegos». Dicho lo cual, Sancho comparece a lomos de su montura ante el mayordomo, el secretario, el maestresala, el médico Pedro Recio y otros más, y presenta su dimisión como gobernador de Barataria en un discurso que cumple aquí reproducir casi entero (dejo fuera dos interlocuciones finales con el mayordomo y el doctor Recio, respectivamente):

-Abrid camino, señores míos, y dejadme volver a mi antigua libertad: dejadme que vaya a buscar la vida pasada, para que me resucite de esta muerte presente. Yo no nací para ser gobernador ni para defender ínsulas ni ciudades de los enemigos que quisieren acometerlas. Mejor se me entiende a mí de arar y cavar, podar y ensarmentar las viñas, que de dar leyes ni de defender provincias ni reinos. Bien se está San Pedro en Roma: quiero decir que bien se está cada uno usando el oficio para que fue nacido. Mejor me está a mí una hoz en la mano que un cetro de gobernador, más quiero hartarme de gazpachos que estar sujeto a la miseria de un médico impertinente que me mate de hambre, y más quiero recostarme a la sombra de una encina en el verano y arroparme con un zamarro de dos pelos en el invierno, en mi libertad, que acostarme con la sujeción del gobierno entre sábanas de holanda y vestirme de martas cebollinas. Vuestras mercedes se queden con Dios y digan al duque mi señor que desnudo nací, desnudo me hallo: ni pierdo ni gano; quiero decir que sin blanca entré en este gobierno y sin ella salgo, bien al revés de como suelen salir los gobernadores de otras ínsulas. Y apártense, déjenme ir, que me voy a bizmar, que creo que tengo brumadas todas las costillas, merced a los enemigos que esta noche se han paseado sobre mí.

-No ha de ser así, señor gobernador -dijo el doctor Recio-; que yo le daré a vuesa merced una bebida contra caídas y molimientos que luego le vuelva en su prístina entereza y vigor; y en lo de la comida, yo prometo a vuesa merced de enmendarme, dejándole comer abundantemente de todo aquello que quisiere.

-¡Tarde piache! -respondió Sancho-. Así dejaré de irme como volverme turco. No son estas burlas para dos veces. Por Dios que así me quede en este ni admita otro gobierno, aunque me le diesen entre dos platos, como volar al cielo sin alas. Yo soy del linaje de los Panzas, que todos son testarudos, y si una vez dicen nones, nones han de ser, aunque sean pares, a pesar de todo el mundo. Quédense en esta caballeriza las alas de la hormiga, que me levantaron en el aire para que me comiesen vencejos y otros pájaros, y volvámonos a andar por el suelo con pie llano, que si no le adornaren zapatos picados de cordobán, no le faltarán alpargatas toscas de cuerda. Cada oveja con su pareja, y nadie tienda más la pierna de cuanto fuere larga la sábana; y déjenme pasar, que se me hace tarde.

4 En la frase inmediatamente anterior, Sancho pide que se «me enjugue este sudor, que me hago agua» (2.53, 1162) pero debe de estar enmascarando la verdadera causa de sus efusiones corporales; las connotaciones escatológicas son insoslayables (Pelorson 2015, 242). 
Los hispanistas no han escatimado esfuerzos en el rastreo de fuentes. A. Redondo (1997) vio reflejos de la tradición carnavalesca en las transformaciones y tribulaciones de Sancho. Estudiando las huellas de Fray Antonio de Guevara -sobre todo, del Relox de príncipes- en el relato sobre el gobierno de Sancho en la Ínsula, H. Chiong Rivero considera que, enmarcada en «un contexto abiertamente carnavalesco», la abdicación de nuestro héroe «apunta a una novelización política que inserta el episodio cervantino en la vena satírica y paródica que Guevara ya había forjado en sus abigarradas obras de crítica sociopolítica» $(2008,160)$. La renuncia del gobernador, asimismo, ha sugerido paralelismos con la recuperación de la «libertad» por Rinaldo, curado de sus amores por Angélica (Orlando furioso, XLII, 65-66; Güntert 1994), con la renuncia «de los héroes bíblicos al mundo y sus vanidades» ${ }^{5}$, y con el episodio del romano Cincinato (Rico 2015, II 704). A su vez, el tratamiento cervantino, en el mismo pasaje, del tema del menosprecio de corte y alabanza de aldea se ha puesto en correspondencia con una famosa letrilla de Góngora ( «Ándeme yo caliente / y ríase la gente» $)^{6}$ y con la «Oda a la vida retirada», de fray Luis de León ( $c f$. Rico 2015, II 704): línea genealógica que, a su vez, propicia la conexión del discurso sanchesco con el horaciano Epodo 2 (cf. Santos 2008, 241-242). Las referencias a Horacio y a la tradición clásica pueden, creo, ampliarse con algún provecho 7 .

De antigua raigambre filosófica y literaria, y caros al poeta de Venusia, son en efecto temas particulares del pasaje cervantino -y de los citados de Góngora o de Fray Luiscomo el de la preferencia por la humildad en libertad frente a las paradójicas servidumbres de una posición elevada, y la disyuntiva aneja de la pobreza despreocupada frente a la «ansiedad en lecho de oro», según palabras de Epicuro (fr.207 Usener); antigua es asimismo la combinación de estos temas con el de la antítesis 'campo / ciudad corte' ( $c f$. la frase «más quiero recostarme a la sombra de una encina en el verano y arroparme con un zamarro de dos pelos en el invierno, en mi libertad, que acostarme con la sujeción del gobierno entre sábanas de holanda y vestirme de martas cebollinas») ${ }^{8}$. El citado Epodo 2 ilustra en alguna medida esa mezcla de temas ( $c f$. vv. 37-38; 49-60; Watson 2003, $113-$ 114); y, dada la coincidencia del texto latino y el castellano en el tema de 'menosprecio de corte y alabanza de aldea', la preferencia del escudero por recostarse «a la sombra de una encina en el verano» revela una procedencia inequívoca (cf. v. 23 libet iacere modo sub antiqua ilice $)^{9}$. También la lírica del vate venusino ofrece tratamientos insignes de los temas mencionados ${ }^{10}$. Pero ya desde las Sátiras sermonea Horacio sobre las ventajas

5 Así, en Santos (2008, 242), quien compara la frase «desnudo nací, desnudo me hallo» con Eclesiastés 5.4 («Como desnudo salió del vientre de la madre, desnudo se tornará»), y «sin blanca entré en este gobierno y sin ella salgo» con la Epístola de Pablo a Timoteo, 6.7 («Nada trajimos al mundo y nada podemos llevarnos de él»).

$6 \quad C f$. Rico (2015, II 704). Los paralelos se localizan, con todo, entre los vv. 3-22 y un pasaje muy preciso del discurso de Sancho («Mejor me está a mí una hoz en la mano que un cetro de gobernador [...] y vestirme de martas cebollinas»; véase infra, sobre posibles raíces clásicas de este pasaje).

7 La edición de Horacio que aquí sigo es la de Klingner (2008), adaptada a los criterios ortográficos de esta Revista.

8 Como recuerda Braund (1989), las escuelas romanas de declamación incluían, entre otros temas típicos para la ejercitación en debates, el de la comparación entre los dos hábitats -Quint.Inst.2.4.24 rusticana uita an urbana potior-; semejante es, en este sentido, la tradición retórica griega (Cairns, 1975). Para la antítesis campo / ciudad en la poesía de Horacio en general, baste aquí remitir a Harrison (2007); para aspectos y obras particulares, véase infra y las nn. 10 y siguientes. Cristóbal López (1992) traza una muy ilustrativa panorámica de la tradición del tema desde la antigüedad grecolatina a nuestros días.

$9 \quad$ El paralelo falta en Santos (2008); sobre otro posible eco horaciano, éste subsidiario, véase n. 46.

10 Cf. v.g. Carm. 2.16, esp. vv. 5-16 (con Nisbet-Hubbard 1978, 258-260); 3.1, esp. vv. 17-24 (el insomnio de los ricos vs. el sueño fácil de los pobres); vv. 46-48 diuitias operosiores; 3.29, esp. vv. 9-16 (con Nisbet-Rudd 2004, 12-14; 19-21; 350-352). Schwarz (2013, 120), Rico (2015, I 826, n. 63; II 587) ven un eco de Carm.3.1, v. 1 
de la simplicidad rústica para el buen vivir ( $c f$. sobre todo 2.2), al tiempo que advierte sobre las peligrosas complicaciones de la vida en la ciudad: así, paradigmáticamente, en la sátira 2.6, que contiene - es la versión más temprana que conservamos de este tema tradicional, y también la mejor, desde un punto de vista literario ${ }^{11}$ - la célebre fábula del ratón rústico y el ratón urbano (Sat.2.6.79-117) ${ }^{12}$. Hasta donde alcanzo a ver, la exegética

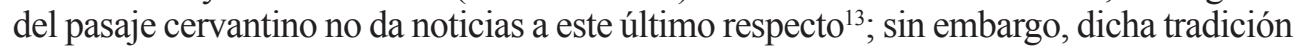
fabulística - de hecho, recreada por ingenios hispanos contemporáneos y anteriores a Cervantes $^{14}$ - presenta llamativas similitudes con el desenlace del relato sanchesco. 'Ratón de campo' a su manera, también el buen escudero huye finalmente de regreso a su hábitat original, siendo el detonante de su espantada -si bien el hambre que pasó de gobernador también habría ayudado a su decisión-justamente el horror a los peligros con que le sorprende la vida en la corte ${ }^{15}$; y si estos paralelismos pueden referirse a más de una versión de la antigua fábula ${ }^{16}$, hay algún detalle que tal vez apunte, específicamente, a la de Horacio ${ }^{17}$. Pero más aún que las Sátiras nos interesan aquí las Epístolas, donde la

Odi profanum uulgus et arceo en 2.16, 826: «Y no penséis, señor, que yo llamo aquí vulgo solamente a la gente plebeya y humilde, que todo aquel que no sabe, aunque sea señor y príncipe, puede y debe entrar en número de vulgo»; en el mismo capítulo cervantino, de hecho, se menciona repetidamente a Horacio.

11 Cf. Cascón Dorado (2003-2004, 88); para la fábula en otras fuentes antiguas y su transmisión posterior, véase también Gutiérrez (2009, 281-296); cf. nn. 16 y 56.

12 Para el tema 'campo / ciudad' en la sátira romana, véase Braund (1989); sobre la elaboración horaciana de la fábula ratonil en West (1974). En Sat.2.7 trata Horacio el tema de la libertad frente a los halagos del lujo y el poder, así como frente a las pasiones y al miedo (esp. vv. 75ss.).

13 Andino Sánchez $(2008,173 ;$ cf. 125-126, 187) cree ver una reminiscencia de la versión horaciana en 2.29, 950: «¿Quién te persigue, o quién te acosa, ánimo de ratón casero, o qué te falta, menesteroso en la mitad de las entrañas de la abundancia?»; más claro es el eco de Carm.3.16.28 inter opes inops, indicado por el mismo estudioso, en la secuencia final de esta misma cita.

14 Cf. el «Enxiemplo del mur de Monferrado et del mur de Guadalajara» (Libro de buen amor, estr. 1370-1386); hay otra versión en el Libro de los gatos (s. XIV); en la «Epístola a Don Francisco de Eraso», de B. L. de Argensola (1604 / 1606); en el Fabulario de Sebastián Mey (1613); véase Chevalier (1999, 89-90); Beltrán (2014, esp. 20-26), rastrea ecos de la fábula en La Celestina (final de la segunda escena del acto noveno).

15 En la versión de Horacio también el ratón de campo -como Sancho- se lo piensa mejor tras el sobresalto final, producido al oírse de improviso «un ingente estrépito de puertas», cuando «la alta casa retumbó por los ladridos de canes molosos» (Sat.2.6.112-115; en otras fuentes, sabido es, provoca el desenlace la irrupción del gato en vez de los ladridos: Chevalier 1999, 89-90); hasta ese momento, el roedor se hallaba repanchingado sobre el lecho convival, disfrutando de una cena exquisita y contento con «su cambio de suerte» (v. 110 mutata sorte). Aquí hay un punto de contraste, ya que, de gobernador, Sancho apenas consigue dar gusto a su paladar, dado el régimen severo que le impone el doctor Recio ( $c f . v . g .2 .47,1097)$. Pero, en cualquier caso, y al igual que en la fábula grecolatina (cf. West 1974, 71-74), la comida (o, ahora, más bien la falta de ella) es un elemento importante en el episodio de Barataria. Tras protestar por el hambre pasada, al fin «le dieron de cenar un salpicón de vaca con cebolla y unas manos cocidas de ternera algo entrada en días» $(2.49,1118)$; pero al día siguiente «levantóse, en fin, el señor gobernador, y por orden del doctor Pedro Recio le hicieron desayunar con un poco de conserva y cuatro tragos de agua fría, cosa que la trocara Sancho con un pedazo de pan y un racimo de uvas» $(2.51,1141 ; c f .1144)$. En su carta de respuesta a D. Quijote, Sancho incluye la expectativa de lujos y gollerías, a la postre desengañada, entre los alicientes que al principio le ilusionaran de su nuevo estado $(2.51,1147)$. Tal insistencia en las tribulaciones dietéticas del gobernador, que cuadran al carácter -nomen, omen-de un personaje aptamente apellidado Panza, cobra posible sentido adicional en una comparación con la fábula de los roedores. El asustado ratón de campo al menos ha logrado antes regalarse el estómago; el relato de Cervantes sobrepuja este modelo en lo que se refiere a la miseria final del protagonista: como hemos apuntado, el motivo de Sancho para el escarmiento -frustración gastronómica y, sobre todo, miedo- es doble (véase n. 17).

16 Cervantes, claro es, estaría familiarizado con la colección de fábulas esópicas conocida como Isopete («Guisopete», en $D Q 1.25,296$; cf. Rico 2015 II, 435; Andino Sánchez 2008, 125-129); en DQ 1 Prólogo, 15, leemos cita de un verso que procede del texto latino de Gualtero el Inglés, Non bene pro toto libertas uenditur auro (De cane et lupo, III, v. 25); véase n. 55.

17 Más arriba en la carta a D. Quijote, Sancho ha declarado pasar en su gobierno «más hambre que cuando andábamos los dos por las selvas y por los despoblados» $(2.51,1147)$. El dato topográfico y la elección léxica 
antítesis 'campo / ciudad' no sólo cobra especial importancia como tema, sino que, de hecho, es consustancial al propio género literario elegido: Horacio aparece aquí escribiendo a amigos y a conocidos desde la distancia, y en la mayoría de los casos, la distancia corresponde a un medio rural ${ }^{18}$. Y de entre las diversas incursiones en este tema del Horacio epistolar ${ }^{19}$, nos interesará sobre todo una curiosa inversión-variación sobre la fábula de los ratones, que ahora se presenta como apólogo protagonizado por humanos (Epist. 1.7.46-98) ${ }^{20}$. Hasta donde sé, la filología cervantina tampoco parece haber reparado en este antecedente, pese a sus llamativas coincidencias con el desenlace de $D Q 2.53$ en lo que se refiere a situación, reacción y evolución de los protagonistas, e incluso motivos y lenguaje metafórico ${ }^{21}$. Es mi propósito a renglón seguido indicar esos puntos de contacto de manera esquemática ${ }^{22}$; la comparación bastará, según espero, para enriquecer de manera sustancial la genealogía literaria del relato sobre Sancho en Barataria, considerado «tal vez, el más importante de la Segunda Parte del Quijote» (Redondo 1997, 191).

Antes de hacer la comparación con $D Q 2.53$, cumple recordar algunos datos sobre esa composición latina. Con razón se ha dicho que la epístola 1 del mismo libro, dirigida a Mecenas, es una carta de dimisión ${ }^{23}$ : no sin ironías ni implícitos autodesmentidos, Horacio rehúsa allí la invitación de su patronus a volver a escribir poesía y, en definitiva, declara 'dimitir' como poeta (en muy poéticos versos, por cierto) para dedicarse a la filosofía moral y los cuidados del alma. Pues bien, la epístola 7 es en cierto modo otra carta de dimisión enderezada al mismo destinatario, aunque digamos que con fecha en blanco y entrada en efecto sólo eventual. Me explicaré. Según cabe inferir de los versos iniciales (vv. 1-13), el patrón de Horacio habría reclamado desde Roma la compañía del poeta, que éste le habría prometido con anterioridad ${ }^{24}$; sin embargo Horacio escurre el bulto alegando excusas de salud y remolonea en su

(«selvas») son interesantes: $c f$. Sat. 2.6.116-117 me silua cauusque / tutus ab insidiis tenui solabitur eruo; Villén de Biedma 1599, 234r.: «la selva y un agujero seguro» (sobre este comentario a Horacio y su uso por Cervantes, véase n. 57); v. 90 uis tu homines urbemque feris praeponere siluis?; Villén de Biedma 1599, 233v.: «las ásperas selvas»); Argensola, «Epístola a Don Francisco de Eraso» (cf. n. 14): «No me dirás, amigo, por qué pasas / la vida en este mísero escondrijo? / ¿Antepones las selvas a las casas, / i al sabor de los más nobles manjares / unas legumbres débiles y escasas? / Ruégote que a este hiermo desampares [...]». El detalle falta en la versión de Gualtero el Inglés (véase nn. anterior y 56). Es conocido el interés de Cervantes por «los sermones al modo de Horacio» (DQ 2.16, 826 y n. 20; Close 1990; $c f$. Schwarz 2013, 119).

18 Epist.1.5 y 14 se presentan como escritas desde la ciudad; 1.12 parece escrita por un Horacio bien informado sobre los asuntos de Roma (vv. 25-29); 1.20, decididamente ficticia, menciona lugares de Roma pero no indica que el poeta se halle en la Urbe; 2.1 no dice nada sobre la dirección del remitente; en 2.2, Horacio pretexta las incomodidades de la vida urbana para justificarse ante Julio Floro por no escribir poesía (vv. 65-86, esp. 84-85).

19 Programáticamente, ya en 1.1 declara Horacio haberse retirado de la actividad poética al igual que el gladiador Vejanio, ya jubilado, se «oculta en el campo» (vv. 1-6); variaciones sobre las bondades de la vida rústica, en 1.7 (véase infra); 1.4.4-5 (cf. vv. 15-16); 1.10.1-25 (cf. v. 50 laetus); 1.14; 1.16.1-16; 1.18.101-112; 2.2.65-80; en 1.8, un deprimido Horacio dice añorar el campo cuando está en la ciudad, y viceversa (cf. Sat.2.7.28-29).Véase Hirth (1985); Ferri (1993); McCarter (2015, 124-189); cf. Jenkyns (2013, 58-62).

20 Sobre este apólogo como inversión de la fábula narrada en Sat.2.6, $c f$. Jenkyns 2013, 59-60.

21 Anotadores y comentaristas no dan noticia al respecto: $c f$. Pellicer (1798); Ideler (1805); Clemencín (1834); Cortejón (1913); Schevill-Bonilla (1941); Gaos (1987); Sevilla-Rey Hazas (1993); Riquer (1997); Sevilla (2014); Rico (2015); tampoco la hay en los estudios que conozco sobre la tradición clásica en Cervantes (véase n. 57).

22 Así pues, y como vengo haciendo hasta ahora en el presente trabajo, limitaré las referencias bibliográficas sobre la epístola latina y otras composiciones horacianas a las mínimas requeridas para una contextualización crítica suficiente.

23 Johnson (1993, 3): «E. 1.1, the dedicatory and programmatic letter of resignation».

24 Pese a McGann (1969, 48-49: «He does not say that Maecenas has asked him to return»), Horacio está en su finca: si sabe que es añorado (v. 2 desideror), Mecenas le habrá escrito reclamándole su compañía (cf. v. 25 quod si me noles usquam discedere). 
finca, deleitable retiro donde se siente un metafórico rey (Epist.1.10.8ss.) ${ }^{25}$. Para no resultar ingrato, el protegido reitera su reconocimiento a Mecenas por «haberle hecho rico» ${ }^{26}$, y lo alaba por ser un patronus de buen juicio a la hora de hacer regalos y de seleccionar a los destinatarios de su favor (vv. 14-24) ${ }^{27}$, pero le expresa su deseo de preservar una relativa independencia y declara estar dispuesto a devolver los beneficios recibidos si el precio de ellos, impuesto por la obligación de gratitud, fuera renunciar a la libertad de sus ratos de ocio y al dominio de su propio tiempo y de su vida, riquezas inigualables que no cambia por todo el oro del mundo (vv. 29-45) ${ }^{28}$ :

Cierta vez por angosto resquicio una flaca raposa se coló en un arcón de cebada y, ahíta, de vuelta 30

ir afuera intentaba, repleta la panza: era inútil. Un tejón le gritó desde lejos: «si quieres salirte, vuelve enjuta al estrecho agujero que enjuta cruzaste.»

Si alguien me acusa invocando esta fábula, a todo $\left[\right.$ renuncio ${ }^{29}$.

Ni harto yo de capones alabo el dormir de la plebe, $\quad 35$ ni por joyas de Arabia mi holganza libérrima trueco ${ }^{30}$. Mi humildad a menudo elogiaste: me oíste llamarte 'Padre' y 'Rey'31 cara a cara; en tu ausencia, no dije [otra cosa: mira tú si podré devolver tan contento tus dones. No sin tino Telémaco, prole del sabio Odiseo, dijo en respuesta: «No es Ítaca sitio que cuadre a [caballos,

pues ni es vasta en llanuras ni pródiga en pasto [abundante; más, Atrida, te cuadra tu obsequio que a mí: [todo tuyo».

Sienta bien lo pequeño al pequeño. No es ya de mi [agrado Roma la real, sino Tívoli ocioso y Tarento apacible.
Forte per angustam tenuis uulpecula rimam

repserat in cumeram frumenti, pastaque

[rursus

ire foras pleno tendebat corpore frustra. cui mustela procul: 'Si uis' ait 'effugere istinc, macra cauum repetes artum, quem macra

[subisti.'

Hac ego si compellor imagine, cuncta resigno;

nec somnum plebis laudo satur altilium nec otia divitiis Arabum liberrima muto.

Saepe uerecundum laudasti, rexque paterque audisti coram nec uerbo parcius absens:

inspice si possum donata reponere laetus.

40 Haud male Telemachus, proles sapientis Vlixei:

'Non est aptus equis Ithace locus, ut neque

[planis

porrectus spatiis nec multae prodigus herbae;

Atride, magis apta tibi tua dona relinquam.'

paruum parua decent; mihi iam non regia

[Roma, 45

sed uacuum Tibur placet aut inbelle Tarentum.

25 Horacio debía este «reino» a la magnificencia de Mecenas, a su vez «rey» de nuestro poeta (cf. Oliensis 1998, 161), según apelación usada por clientes romanos para sus patrones (vv. 37-38; cf. n. 31).

26 V. 15 tu me fecisti locupletem; cf. Epod.1.31-32; véase Bowditch (2001, 211-246).

27 Sobre la implícita autoalabanza de este elogio a Mecenas, véase Hawyard (1986, 18).

28 Mi traducción forma parte de una edición bilingüe de las Epístolas de Horacio, en vías de publicación.

29 El subtexto: si quieres liberarte de las servidumbres del clientelazgo y recuperar la independencia, devuelve antes todas las riquezas recibidas de tu patrón, que tanto te han hecho «engordar».

30 La plebe goza de un sueño envidiable porque no la acucian las preocupaciones que al poderoso o al rico (dormir en el campo tiene parecidas ventajas, $c f$. HoR.Carm.3.1.21-22 somnus agrestium / lenis uirorum; Epist.1.10.18; 2.2.77-80; véase supra y n. 10), y sobre todo porque sus más apretados recursos la fuerzan a cenar poco, cf. Eclesiastés 5.11: «Dulce es el sueño del obrero, coma mucho o coma poco; el que se harta de riquezas no logra conciliar el sueño». Hombre no siempre frugal (cf. v.g. Epist.1.5.2; 1.15; Sat.2.7.29-45) y de pasar desahogado (de nuevo, gracias a Mecenas), Horacio dice no caer en el fariseísmo o la inconstancia de alabar aquel higiénico hábito tras atiborrarse de manjares (cf. McGann 1969, 51; Mayer 1994, 164); pero, al mismo tiempo que no hace ascos a esas y otras comodidades, se muestra preparado para renunciar a ellas si el precio de poseerlas es perder la libertad y el dominio de su tiempo.

31 Son tratamientos habituales del cliente al patrón romano; véase supra n. 25. 
La fábula de la raposa y las palabras de Telémaco al rey Menelao (Hoм.Od.4.601608) constituyen los dos primeros exempla a los que acude Horacio para justificar su actitud frente a Mecenas. Pero el que principalmente nos interesa ahora es el tercer exemplum, con mucho el más extenso (de hecho, alcanza hasta el final de la epístola). Se trata de una anécdota ambientada en Roma. No hay seguridad sobre si es invención del poeta, o relato de un caso real transmitido oralmente ${ }^{32}$. Uno de los protagonistas, llamado Filipo, parece inspirarse en un personaje histórico ${ }^{33}$. Horacio lo presenta como abogado célebre (cf. vv. 46 causisque Philippus agendis / clarus), oficio al que, de modo apto al asunto de la narración, presta nombre el mismo sustantivo (patronus) que designa en latín al protector de un cliens: como es sabido, aquél tenía entre otras obligaciones típicas, la de ofrecer a su protegido asistencia legal gratuita. El otro personaje es un humilde liberto, Volteyo Mena; no hay de él en las fuentes antiguas más noticia que lo aquí narrado por Horacio (vv. 46-98) s. $^{34}$

Hombre animoso y bizarro, abogado eminente, Filipo regresaba a las dos más o menos de hacer sus ${ }^{35}$

[deberes

lamentando -pues ya era mayor- que estuvieran

[tan lejos

las Carinas del Foro, y se cuenta que vio en la

$$
\text { [indolente }
$$

sombra de una barbería a un sujeto muy bien

[afeitado

que se estaba cortando a navaja calmoso las uñas.

Dijo Filipo: «Demetrio» - era un mozo que oía

[muy presto

sus mandados- «pregúntale y dime cuál es su linaje, y quién es, y de qué condición, de qué padre o

[patrono.»

Va y regresa y le cuenta: «Apellídase Mena Volteyo; 55 pregonero, de magro peculio, intachable y con fama de afanarse y holgar, de ganar y gastar cuando debe; se contenta con un lar seguro y humildes amigos
Strenuus et fortis causisque Philippus agendis clarus, ab officiis octauam circiter horam

dum redit atque foro nimium distare Carinas

iam grandis natu queritur, conspexit, ut aiunt,

50 adrasum quendam uacua tonsoris in umbra

cultello proprios purgantem leniter unguis. 'Demetri' (puer hic non laeue iussa Philippi

accipiebat) 'abi, quaere et refer, unde domo, quis, cuius fortunae, quo sit patre quoue patrono.'

It, redit et narrat Volteium nomine Menam, praeconem, tenui censu, sine crimine, notum et properare loco et cessare, et quaerere et uti, gaudentem paruisque sodalibus et lare certo

32 Todo depende del crédito que demos a ut aiunt (v. 49): Hiltbrunner (1960, 296); Horsfall (1993, 65-66).

33 Lucio Marcio Filipo (cónsul en el 91 a.C.): Münzer (1930); Horsfall (1993, 66), Mayer (1994, 166).

34 Valiéndome de una licencia empleada por los escritores romanos, en mi versión trueco a conveniencia el orden del nomen (Volteius) y el cognomen (Mena) del personaje. Libertus / libertinus no aparece en toda la epístola, pero el cognomen griego Mena delata la condición social de Volteyo (Horsfall 1993, 70-71; Mayer 1994, 167). Tal estatus favorece su asimilación con Horacio en paralelo a la de Filipo con Mecenas (Horacio fue hijo de un liberto), si bien las correspondencias 'Horacio Volteyo / Filipo Mecenas' no son equivalencias exactas o inequívocas a lo largo del apólogo; $c f$. Horsfall (1993, 92-94), Oliensis (1998, 161-165). Más allá de 1.7, el de la libertad es tema central y poliédrico en Epístolas 1, cf. Johnson (1993); McCarter (2015, 4-18) estudia el concepto de libertad moderada -equidistante entre la mera libertas y la seruitus - predominante en la perspectiva del Horacio epistolar, observando que dicho concepto encuentra un símbolo apropiado en la figura social del liberto (véase pp. 124-160, sobre Epist.1.7). También la libertad es asunto importante en el discurso de Sancho (2.53, véase infra) y en las reflexiones de Don Quijote (2.58) sobre la experiencia vivida en Barataria (véase infra).

35 Aquí y más abajo (v. 71 post nonam uenies; $c f$. n. 39) adapto redondeando las referencias horarias del original al sistema moderno (Mayer 1994, 166). 
y, después del trabajo, con ir a los juegos y al

[Campo.»

«De su boca me place escuchar cuanto estás

[refiriendo;

dile que venga a cenar». Mena no daba crédito:

[mudo

de estupor se quedó. Bueno, abrevio. Responde:

[«Qué amable;

gracias, mas no». «¿Que él a mí se me niega?»

$[\ll$ Se niega el canalla:

te desprecia o te teme». Encontrábase al día siguiente

Mena vendiendo retales al vulgo que va de trapillo. 65

Se adelanta y se acerca Filipo a decir buenos días.

Pretextóle Volteyo el trabajo y las mil ataduras

del negocio: «Por eso no fui con el alba a tu casa

ni te he ido a ver antes por eso» ${ }^{37}-«$ Pues júzgate ${ }^{38}$

[absuelto

si hoy vinieres conmigo a cenar.» «Como

[gustes.» «Entonces,

ven después de las tres ${ }^{39}$. Ahora, aumenta

[animoso tu hacienda.»)

En la cena charló de cuanto hay que decir y callarse; se le manda por fin a dormir. Viose pronto acudiendo a menudo al anzuelo escondido, cual pez: de mañana cliente, a diario en su mesa. Llegaron las Ferias

\section{[Latinas,}

y, obligado, acompaña a Filipo a su casa de campo.

Iba en un carro de jacas; el clima y el agro sabinos de alabar no paraba; Filipo lo advierte y se ríe, y con tal de buscarse doquiera el solaz de unas risas, va y le da siete mil y otro tanto promete fiarle de sestercios; lo anima a comprarse un campito

[y Volteyo

se lo compra. Y, en fin, para no entretenerte más

[tiempo

del preciso: era un hombre elegante y se vuelve

$$
\text { [un paleto, }
$$

et ludis et post decisa negotia Campo.

60 'Scitari libet ex ipso quodcumque refers:

[dic

ad cenam ueniat.' non sane credere Mena,

mirari secum tacitus. Quid multa? 'benigne,'

respondet. 'Neget ille mihi?' 'Negat inprobus

[et te

neglegit aut horret.' Volteium mane Philippus

uilia uendentem tunicato scruta popello

occupat et saluere iubet prior; ille Philippo

excusare laborem et mercennaria uincla,

quod non mane domum uenisset, denique

[quod non

prouidisset eum. 'Sic ignouisse putato

70 me tibi, si cenas hodie mecum.' 'ut libet.' 'ergo

post nonam uenies; nunc i, rem strenuus auge.'

Vt uentum ad cenam est, dicenda tacenda locutus tandem dormitum dimittitur. hic ubi saepe occultum uisus decurrere piscis ad hamum,

mane cliens et iam certus conuiua, iubetur

rura suburbana indictis comes ire Latinis. inpositus mannis aruum caelumque Sabinum non cessat laudare. uidet ridetque Philippus, et sibi dum requiem, dum risus undique quaerit, 80 dum septem donat sestertia, mutua septem promittit, persuadet uti mercetur agellum.

mercatur. ne te longis ambagibus ultra quam satis est morer: ex nitido fit rusticus atque

36 Se refiere al Campo de Marte, junto al Tíber, lugar de esparcimiento donde los romanos celebraban pícnics o hacían ejercicio al aire libre.

37 Se recordará que el cliens tiene, entre otras obligaciones con su patronus, la de ir cada día al alba a casa de éste a presentarle sus respetos (salutatio matutina).

38 Adapto libremente en mi versión el tono forense que parece imprimir Horacio al habla del abogado Filipo a través del imperativo de futuro putato, de gusto arcaico y uso frecuente en textos legales ( $c f$. Powell 2005, 127).

39 La hora nona, que en verano duraría de las $2: 31$ a las 3:46, era habitual para la cena romana, si bien los laboriosos abogados solían cenar más tarde (Horsfall 1993, 78-79). 
no habla más que de arados, de surcos, de olmedos

[y vides,

muere de afán, lo envejece el amor de poseer.

[Mas entonces

un ladrón se llevó sus ovejas, la peste sus cabras, la cosecha engañó su ilusión, reventó el buey arando. Afligido por tanta ruina, en mitad de la noche un rocín agarró y fuese a ver, irritado, a Filipo. Éste, apenas lo vio desgreñado y mugriento, le dijo

«Me pareces pasarte, Volteyo, de estricto y atento». «Desgraciado, por Pólux, podrías llamarme, patrono, si quisieras ponerme apellido veraz y atinado.

Por tu genio y tu diestra y penates te ruego y te pido: haz que vuelva mi vida anterior». Quien apenas

[advierta

cuánto mejor que lo ansiado es aquello que necio [desecha,

vuelva al instante a buscarlo, si es cierto y verdad

[lo que dicen:

que se mide de acuerdo a su talla y su pie cada sulcos et uineta crepat mera, praeparat ulmos,

85

inmoritur studiis et amore senescit habendi.

Verum ubi oues furto, morbo periere capellae, spem mentita seges, bos est enectus arando: offensus damnis media de nocte caballum arripit iratusque Philippi tendit ad aedis. quem simul aspexit scabrum intonsumque

[Philippus:

'durus' ait, 'Voltei, nimis attentusque uideris esse mihi.' 'Pol, me miserum, patrone, uocares, si uelles' inquit 'uerum mihi ponere nomen. quod te per Genium dextramque deosque Penatis obsecro et obtestor, uitae me redde priori.'

qui semel aspexit quantum dimissa petitis

praestent, mature redeat repetatque relicta.

metiri se quemque suo modulo ac pede uerum est.

[quisque.

Entre las historias de Sancho y de Volteyo pueden señalarse las siguientes coincidencias:

1. Asunto general y evolución de los protagonistas. La transformación que ambos experimentan es parecida. Son hombres originalmente sencillos y felices en la simpleza de sus vidas anónimas. Sin embargo, no son del todo inmunes a la tentación del poder o de la riqueza. La ambición (Sancho) y la codicia (Volteyo) parecen nublarles el sentido de la medida ${ }^{40} \mathrm{y}$, cuando dan colmo a sus aspiraciones, ciertos gajes imprevistos de su nuevo oficio se lo hacen pasar muy mal. Finalmente se arrepienten y la transformación se revierte: uno y otro descubren que no estaban hechos para tan exigentes ocupaciones y reclaman el regreso a sus anteriores vidas.

2. El papel jugado por unos patrones bromistas. Hombre humilde y feliz, Volteyo cambia de vida y carácter cuando traba conocimiento con Filipo; es invitado todos los días a cenar -acude «a menudo al anzuelo escondido, cual pez» (v. 73)- y se convierte en cliens del prestigioso patronus: éste le mete el gusanillo de la codicia y lo ayuda económicamente a hacerse propietario de un agellus. A su vez Sancho Panza adquiere el gobierno de la Ínsula bajo el patrocinio de los Duques, en cuyo castillo se hospeda y cuya mesa comparte. Por otra parte, de Filipo se dice que buscaba a toda costa una ocasión de risa cuando ayuda a su cliente a ascender de estatus

40 Volteyo (v. 85): immoritur studiis et amore senescit habendi. Antes de tomar posesión como regidor, Sancho alega la curiosidad hacia la novedosa experiencia como el motivo principal de su interés por el cargo, negando por el contrario que lo guíe la codicia $(2.42,1057)$. Pero hablándole a su rucio, reconocerá: «me subí sobre las torres de la ambición y de la soberbia» $(2.53,1162 ; c f .2 .36,1018)$. Sin embargo, a la vista de su desempeño no cabe imputar afán de enriquecerse a Sancho: «ni pierdo ni gano; quiero decir que sin blanca entré en este gobierno y sin ella salgo, bien al revés de como suelen salir los gobernadores de otras ínsulas» $(2.53,1163)$. Sobre el adicional interés hedonista de Sancho por su cargo en Barataria $(2.51,1147)$, véase n. 15. 
(v. 77-81 $)^{41}$; se recordará que, a su vez, la Barataria adjudicada a Sancho es una localidad $^{42}$ convertida toda ella, con sus habitantes como figurantes, en escenario de una farsa organizada por los Duques, afanosos de divertirse con la fantasiosa ingenuidad de los pobres protagonistas: fenomenal máquina y traza que no desmerecen, si nos trasladamos a la ficción moderna, de tinglados como el que se representa en el largometraje El Show de Truman ${ }^{43}$. Las proporciones y el escenario de la burla son diferentes en uno y otro texto, pero es llamativa la coincidencia en las razones, poco edificantes, que invitan a los poderosos a enaltecer a sus protegidos ${ }^{44}$.

3. Desengaños: Vrbs y rus, entre la corte y el campo. Tras su desastrada metamorfosis, Sancho se reencuentra, aliviado, con su verdadera identidad en la simpleza de su anterior vida rústica; en su discurso de renuncia, ya se ha visto, ocupa un lugar importante el tópico del menosprecio o, más bien aquí, desengaño de corte y alabanza de aldea. Los problemas de Volteyo empiezan precisamente cuando se convierte en un rusticus (vv. 83-94). Antes era un urbanita que vivía tranquilo y feliz en Roma: trabajando cuando debe, y disfrutando cuando toca de los ratos de asueto con familia y amigos; emblemática (y programática) de lo último es su presentación en una barbería, lugar asociado ya en el imaginario socio-cultural antiguo al esparcimiento masculino ${ }^{45}$, y que parece introducir en la viñeta horaciana evocaciones de la Arcadia por vía de un sutil guiño intertextual ${ }^{46}$. Uno y otro personaje viajan en sentidos contrarios, sí, pero transitan entre parecidos escenarios vitales (del campo a la corte, Sancho; de la ciudad al campo, Volteyo), y recorriendo itinerarios espirituales que al cabo paran en el desengaño.

4. Tema y moraleja (I): libertas. Las servidumbres del poder (Sancho) o de la riqueza (Volteyo) hacen escarmentar a ambos personajes, que finalmente optan por recuperar la libertad de su perdida humildad. Sancho pide: «dejadme volver a mi antigua libertad»; «más quiero recostarme [...] en mi libertad, que acostarme con la

41 Parejo tipo humano reaparece en las epístolas horacianas bajo el nombre de Eutrápelo (1.18.31-36): un patrón que empujó a un cliente a la desgracia a base de enriquecerlo, y cuyo nombre en griego significa 'el, ingenioso, el ocurrente'.

42 Identificada con Alcalá del Ebro por los estudiosos.

43 Así en Gómez Montoro (2010). Aunque la situación y el propósito de la farsa son diferentes, recuérdese quizá también Bienvenido Mister Marshall, de Berlanga.

44 No hay coincidencia, quizá, en la psicología que subyace a esas razones. En el caso de los Duques parece mandar el mero aburrimiento de una aristocracia ociosa. Las razones de Filipo son más complejas. Es hombre de humor malicioso, ya se ha dicho, y busca la diversión aun a costa de la infelicidad ajena, pero también parece moverle la envidia hacia un inferior social al que íntimamente sabe más feliz y libre que él (cf. Horsfall 1993, 93-94, que atribuye al personaje un «carattere palesemente cattivo»): su desquite consiste en promoverlo económicamente (cf. supra y nn. 24-27, sobre Horacio enriquecido por Mecenas). Esclavizado por las obligaciones hacia el protector, el cliens Volteyo en cierto modo se convierte a su pesar, y sin saberlo, en un scurra de Filipo: un comensal regular en su mesa, que parlotea sin tasa en sus cenas (v. 72), y, en definitiva, sirve para hacer reír a su patrón.

45 Cf. Sen.Ben.12.3; Svet.Aug.79.1; Porph. ad Hor.Sat.1.7.3; Horsfall (1993, 67).

46 Está en uacua tonsoris in umbra (v. 49). Sobre el sentido exacto especula Horsfall (1993, 67): «nella ombra della bottega, o all'aria aperta? Sotto un albero?»); «en el antepuerta de la officina de un barbero» (Villén de Biedma 1599, 261v.); en todo caso, el detalle sugiere una correlación de Mena Volteyo con el Títiro de Verg.Ecl.1.4 tu, Tityre, lentus in umbra (Stégen, 1963, 50; Oliensis 1998, 162), y hace pensar en «una scena da locus amoenus urbano» (Horsfall 1993, 67). La frase de Sancho «más quiero recostarme a la sombra de una encina en el verano», que parece inspirada sobre todo en el Epodo 2 (véase supra), quizá mire también hacia el modelo virgiliano (Ecl.1.1 Tityre, tu patulae recubans sub tegmine fagi), bastante frecuentado por la imitatio aurisecular, como también lo fue en general el motivo del sub arbore quadam (Cristóbal López 1980, 148-188, esp. 170-188). Ejemplos en el Quijote son 1.27, 330 (de posible fuente virgiliana); 2.12, 787; 2.60, 1219, n. 2; 2.68, 1291, n. 22 (explotación cómica del motivo); sobre escenarios pastorales en el Quijote, véase Finello (1994, sobre todo 65-69). 
sujeción del gobierno [...]». En la historia de Volteyo no aparece la palabra liber o libertas, si bien se deja entender su condición de liberto del personaje, del todo simbólica en el relato (véase n. 34); hablando de sí mismo y de su modelo ideal de vida sí hace uso del término Horacio, del que es en buena medida trasunto aquel personaje (vv. 35-36): nec / otia diuitiis Arabum liberrima muto ${ }^{47}$.

5. Tema y moraleja (II): decorum. Volteyo y Sancho comprenden que la felicidad depende de reconocer los límites y medida $\operatorname{propios}^{48}$ y lo que sienta bien a cada cual. Volveremos sobre esto, pero de momento destaco dos puntos. Horacio escribe en la misma epístola, antes de narrar la historia de Volteyo, paruum parua decent, (v. 44), donde el verbo alude a un familiar concepto estético y moral, el de decorum. Sancho: «bien se está cada uno usando el oficio para que fue nacido»; el contexto sugiere que quizá Cervantes fuese consciente de las connotaciones filosóficas del término 'oficio', perteneciente al título de una importante fuente grecolatina, conocida por él mismo, de la doctrina a la que alude su frase ${ }^{49}$.

6. Expresiones, motivos y metáforas.

6.1. El deseo de volver a la vida pasada, tras la «muerte» experimentada en la nueva condición.

Sancho: «dejadme volver a mi antigua libertad; dejadme que vaya a buscar la vida pasada». Volteyo-Horacio: uitae me redde priori (así, el liberto escarmentado); redeat repetatque relicta (el poeta, en la moraleja). Nótese que el mensaje se formula en imperativo («dejadme» / redde), y va dirigido a los poderosos: los Duques (aunque los receptores inmediatos sean los del séquito del gobernador, arriba mencionados), y el patronus Filipo, respectivamente. Volteyo «muere de afán, y envejece de amor de poseer»; a su vez, Sancho quiere «resucitar de la muerte presente.»

6.2. Actividades campesinas.

Sancho: «Mejor se me entiende a mí de arar y cavar, podar y ensarmentar las viñas, que de dar leyes ni de defender provincias ni reinos»; protagonizando la inversión ya explicada del topos Vrbs - rus, Volteyo se vuelve para su desgracia un rusticus, y «no habla más que de arados, de surcos, de olmedos y vides» (v. 84). Siendo campesinos ambos personajes, la coincidencia no es per se extraordinaria; sí podría ser significativa al concurrir con los demás paralelismos.

6.3. Símbolos del mensaje moral: la vestimenta, la talla corporal, el calzado y el pie.

La humildad indumentaria de cuando eran ambos pobres y felices es otro símbolo compartido. Desengañado, Sancho prefiere un zamarro de dos pelos en invierno a las «martas cebollinas $»^{50}$; antes de conocer a Filipo, Volteyo vende retales «a la plebe

47 Cf. Epist.1.10.6-11 y, sobre todo, 39-40: Sic, qui pauperiem ueritus potiore metallis / libertate caret, etc., pasaje que interesa al estudio de $D Q 2.58$ (véase infra y nn. 55-56).

48 Variante del socrático ‘conócete a ti mismo', presente en $D Q 2.42,1059$ (véase Rico 2015, II 674; Barnés Vázquez 2009, 106-107).

49 Horacio usa el lexema al principio del apólogo (v. 47; cf. v. 8 officiosaque sedulitas). En el De officiis, como se

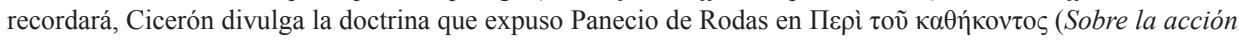
apropiada). Sobre el influjo de Panecio y del De officiis en Horacio, principalmente en las epístolas, véase McGann (1969, 9-32); Johnson (1993, 90-92); sobre la huella de la obra ciceroniana en el final de Epist.1.7 véase infra, § 6.3. Para la influencia de la misma obra en Cervantes, $c f .2 .60,1228$, con la n. 49 de Rico (2015); Barnés Vázquez (2009, 196-197 y n. 30).

50 El decoro en el atuendo es aspecto sobre el que aconseja recurrentemente Don Quijote al gobernador (v.g., $c f$. $2.51,1144-1145 ; 2.42,1057)$. 
que va de trapillo»: él era uno de esos benditos simples ${ }^{51}$. Pero más importante es la insistencia de Sancho, hacia la conclusión de su discurso, en referencias metafóricas al pie, la pierna y el calzado, y ello en un contexto alusivo a la doctrina del decorum (cf. supra, § 5): «y volvámonos a andar por el suelo con pie llano, que si no le adornaren zapatos picados de cordobán, no le faltarán alpargatas toscas de cuerda [...] y nadie tienda más la pierna de cuanto fuere larga la sábana». Horacio concluye la historia de Volteyo, al tiempo que la epístola misma, con análoga metáfora y moraleja: «que se mide de acuerdo a su talla y su pie cada quisque» (v. 98) ${ }^{52}$. Al hilo de este juego de imágenes, en fin, ambos autores coinciden en instruirnos sobre la necesidad que cada hombre tiene de conocer su medida para conducirse felizmente por la vida; un elemento que, en el tratamiento dispensado por Horacio, sugiere influjos de noción y lenguaje procedentes del ciceroniano De officiis (véase supra $\S 5$, y n. 49) ${ }^{53}$.

Estos son los paralelos principales. Se pueden detectar otros ${ }^{54}$. Y no sólo en $D Q$ 2.53. En capítulo posterior, el Ingenioso Hidalgo discurrirá amargamente sobre la experiencia vivida en la compañía de los poderosos, desahogándose con reflexiones como esta $(2.58,1195)$ :

[...] que las obligaciones de las recompensas de los beneficios y mercedes recebidas son ataduras que no dejan campear al ánimo libre.

En el discurso de Sancho, ya lo vimos, se insistía en el tema de la libertad (supra, § 4). Sin embargo, la idea expresada por Don Quijote en 2.58 como moraleja al «fatigado fin y remate» del gobierno de Sancho -las mercedes y beneficios de los poderosos son ataduras de la libertad- no aparece expresamente en el discurso de renuncia pronunciado por Sancho en 2.53 , y en cambio proporcionaría un buen epígrafe a la epístola horaciana 1.7. Pero las convergencias de 2.58 con Horacio parecen acumularse si tenemos en cuenta, además, el vibrante exordio del breve discurso de Don Quijote, en el mismo capítulo:

51 La vestimenta da pie a metáforas de contenido moral recurrentes en Epístolas 1, cf. Mayer (1994, 107, n. a 1.1.95 pexae; contrástese Sat.1.3.29-34); para la imagen afín del calzado, véase infra y nn. 52-53; sobre el cultus corporis -en especial, la manicura- véase n. 54 y Miralles Maldonado (1997).

52 Cf. también Epist.1.10.42-43, en un contexto afín al de 1.7 (véase n. siguiente): Cui non conueniet sua res, ut calceus olim / si pede maior erit, subuertet, si minor, uret; véase Mayer (1994, 187); Otto (1890, 64).

53 Horacio (v. 98): Metiri se quemque suo modulo ac pede uerum est; cf. Cic.Off.1.31.110 ea tamen (i.e. uniuersa natura) conseruata propriam nostram sequamur, ut etiamsi sint alia grauiora atque meliora, tamen nos studia nostra nostrae naturae regula metiamur; cf. Hayward (1986, 15).

54 Seguramente, menos significativos. Uno se refiere al motivo del cultus personal (cf. nn. 51-52) y, en particular, al cuidado del pelo y uñas. Filipo le echa el ojo a Volteyo cuando el liberto urbano estaba en una tranquila barbería, bien afeitado (adrasum quendam) y cortándose plácidamente las uñas (vv. 50-51); al final, ya rústico pero infeliz, aparece mugriento e intonso ante su patrón (scabrum intonsumque; $c f$. n. 46). Sea por influjo horaciano o por simple coincidencia casual, los cuidados de barbería figuran en algunos lances de la estancia de Don Quijote y Sancho junto a los Duques; el primer consejo que Don Quijote imparte a Sancho antes de hacerse cargo de la Ínsula, es que «seas limpio y que te cortes las uñas, sin dejarlas crecer» $(2.43,1062)$; compárese la queja de Sancho, ya esclavizado por su absorbente cargo: «La ocupación de mis negocios es tan grande, que no tengo lugar para rascarme la cabeza, ni aun para cortarme las uñas [...]» $(2.51,1147)$. En fin, cabe observar que tanto a Sancho como a Volteyo los vemos, al final de cada episodio (en el Quijote está a punto de amanecer; en Horacio, es mitad de la noche) apareciendo a lomos de poco donosas cabalgaduras (el proverbial asno y un rocín [caballus], respectivamente), justo antes de presentar cada cual su renuncia. 
La libertad, Sancho, es uno de los más preciosos dones que a los hombres dieron los cielos; con ella no pueden igualarse los tesoros que encierra la tierra ni el mar encubre.

Una fuente principal de este último pasaje -conviene advertirlo- probablemente esté en la Arcadia de Lope de Vega (1598) ${ }^{55}$. Pero Lope, a su vez, ha reelaborado un tema del que Horacio ofrece repetidas versiones en Epistolas $1^{56}$. Entre ellas, la correspondiente a 1.7, tan rica en paralelos con el final de $D Q 2.53$, según he intentado mostrar: se recordará de nuevo que allí leíamos, como corolario a la fábula de la raposa, una decidida afirmación de la libertad personal como bien supremo y, en cualquier caso, preferible a los más preciosos bienes materiales (vv. 35-36): nec / otia diuitiis Arabum liberrima muto; véase supra $\S$ 4). Así pues, vemos que en 2.58 Cervantes alude a 2.53, pasaje reminiscente de la epístola 1.7 de Horacio, pero lo hace reelaborando -Lope mediante- un tema tratado por Horacio en los vv. 35-36 de la misma epístola y, lo que es aquí más significativo, incluyendo un elemento («las obligaciones [...]») que no aparece explícito en 2.53 y sí, por el contrario, en los versos latinos. En otras palabras: se diría que Cervantes piensa en la epístola 1.7 de Horacio al evocar, en 2.58, los compases finales de 2.53; si ello es así, el propio autor prestaría, en 2.58, confirmación indirecta a la hipótesis defendida en este trabajo: el relato sobre Volteyo sirvió de modelo a la escena del adiós de Sancho a Barataria.

Contra esta conclusión general, como contra toda la argumentación que a ella conduce, difícilmente cabe objetar que las semejanzas presentadas entre ambos textos se deban a un azar de coincidencias poligenéticas. Algunas de las semejanzas son, sin duda, lo suficientemente tenues como para consentir esa explicación (véase n. 54). Pero hay, creo, un número suficiente de paralelismos significativos; y si esta acumulación no pareciera por sí misma prueba concluyente, recuérdese la importante presencia de Horacio, reconocida por el Cervantismo, entre las lecturas del autor del Quijote $^{57}$. La memoria literaria de Cervantes es, sin duda, un crisol

55 «¡Oh libertad preciosa, / no comparada al oro / ni al bien mayor de la espaciosa tierra! / Más rica y más gozosa / que el precioso tesoro», etc. No encuentro esta probable fuente en Rico (2015 II, 714), donde en cambio sí aparece un paralelo del Guzmán de Alfarache no menos digno de consideración.

56 Junto a 1.7. 35-36, cf. 1.10.8-11; 39-40 Sic, qui pauperiem ueritus potiore metallis / libertate caret, etc. (para otra posible fuente no horaciana de Lope, véase infra en esta nota). La cuestión sobre $D Q 2.58$ y el pasaje de la Arcadia se traba, más problemáticamente de lo que cabe resolver aquí, con una cuestión sobre la escena ficticia de $D Q 1$ Prólogo. Baste recordar que el anónimo personaje de esa escena le aconsejaba allí al autor que, con cualquier pretexto, trufase su novela de latinajos para así posar de culto ante sus lectores, y entre otros ejemplos prácticos le proponía que, si trataba de la libertad, sacase a relucir el hexámetro Non bene pro toto libertas uenditur auro, y en el margen citara «a Horacio o a quien lo dijo». El verso en cuestión procede, sabido es, de las fábulas esópicas de Gualtero el Inglés (De cane et lupo, III, v. 25; véase Rico 2015, I 15, n. 58; II 332); tampoco cabe aquí discutir sobre el sentido de este titubeo sobre el autor de la cita por parte de Cervantes ( $c f$. Marasso 1954, 225-226; cf. Sevilla 2014, 97, n. 51).

57 Marasso (1954) consideró el Quijote el libro más horaciano en lengua castellana, y razonó que Cervantes habría manejado el comentario con paráfrasis de Horacio de Villén de Biedma (1599; $c f$. nn. 17 y 46); el mismo estudioso declaró poseer un ejemplar del impreso de Villén con apostillas manuscritas cuya «letra es la misma de Cervantes» (p. 136; véanse en las pp. 224-229). Sobre este comentario, véase también v.g. Menéndez y Pelayo (1952, 88-89); Alcina (2005); Marías (2016, 7-12); sobre Villén como intermediario entre Horacio y Cervantes, cf. también Colahan (2012); López-Cañete Quiles (2015), y López-Cañete Quiles (en prensa). En su competente registro de ecos horacianos en Cervantes, Schwarz (2013) no incluye, sin embargo, los aquí estudiados (paralelos de Sat., Epist. y Ars, en pp. 112-123); lo mismo cabe decir de Andino Sánchez (2008, 147-188). Apunto aquí otra huella: «Mudan el cielo, y no las costumbres, los que en ellas tal vez hicieron asiento» (El amante liberal; variación sobre Epist.1.11.27 caelum, non animum mutant qui trans mare currunt). Sobre la tradición grecolatina y el Quijote, véase también Navarro Antolín (2006); López Férez (2005, 2008), Barnés Vázquez (2009). 
riquísimo de materiales diversos, que el novelista supo amalgamar y procesar artísticamente a lo largo de su actividad merced a un «deslumbrante poder de asimilación y de síntesis» ${ }^{58}$. La comparación con el final de 2.53 permite, legítimamente, incorporar a aquel bagaje la epístola horaciana 1.7; lo mismo cabe concluir al respecto de otras referencias clásicas, aquí señaladas, entre las que Horacio tiene parte principal: especialmente, la fábula del ratón de campo y el ratón de ciudad. Sin duda, la genealogía literaria del pasaje quijotesco no excluye otras confluencias, como las indicadas desde el Hispanismo; si la principal influencia viene o no de la literatura grecolatina, es alternativa que dejo al mejor criterio y elección de cervantistas: que doctores tiene la Iglesia y, como dice Sancho Panza, bien se está San Pedro en Roma.

\section{Bibliografía}

\section{Fuentes (ediciones y comentarios)}

\subsection{Horacio}

Klingner, F. (2008), Horatius, Opera. Edidit F. Klingner, Berolini et Novi Eboraci (reimpr. de la $3^{\text {a }}$ ed. de Leipzig, 1959).

Nisbet, R. G. M. - Hubbard, M. (1978), A Commentary on Horace, Odes, Book II, Oxford. Nisbet, R. G. M. - Rudd, N. (2004), A Commentary on Horace: Odes, Book III, Oxford.

Villén de Biedma, J. (1599), Q. Horacio Flacco Poeta Lyrico Latino. Sus obras con la declaración Magistral en lengua Castellana por el Doctor Villén de Biedma, Granada.

Watson, L. (2003), A Commentary on Horace's Epodes, Oxford.

\subsection{El Quijote}

Clemencín, D. (1839), M. de Cervantes Saavedra, El ingenioso hidalgo don Quixote de la Mancha, compuesto por Miguel de Cervantes Saavedra; y comentado por Diego Clemencin. Parte II, tomo VI, Madrid.

Cortejón, C. (1913), El ingenioso hidalgo Don Quijote de la Mancha compuesto por Miguel de Cervantes Saavedra. Primera edición crítica [...] por D. Clemente Cortejón [...] continuada por Juan Givanel Mas y Juan Suñé Benajes. Segunda parte, tomo VI, Madrid.

Gaos, V. (1987), Miguel de Cervantes, El ingenioso hidalgo D. Quijote de la Mancha. Edición crítica y comentario de V. Gaos, 3 vols. Madrid.

Ideler, L. (1805), Notas al ingenioso hidalgo D. Quixote de la Mancha, dispuestas por Luis Ideler. Precede la Vida de Miguel de Cervántes [sic] Saavedra escrita por D. Juan Antonio Pellicer. Tomo II, Berlín.

Pellicer, J. A. (1798), El Ingenioso Hidalgo Don Quijote de la Mancha, compuesto por Miguel de Cervantes Saavedra. Nueva edición [...] por D. Juan Antonio Pellicer, Parte segunda, vol. 8, 1798.

Rico. F. (2015), M. de Cervantes, Don Quijote de la Mancha. Edición del Instituto Cervantes (1605, 1615, 2015). Dirigida por Francisco Rico, con la colaboración de Joaquín

58 Así el británico Close (2015, LXXIII), antes de conceder en consecuencia que «el Quijote puede equipararse con la obra de Shakespeare». 
Forradellas, Gonzalo Pontón y el Centro para la Edición de los Clásicos Españoles, 2 vols., Madrid.

Riquer, M. de (1997), Miguel de Cervantes, Don Quijote de la Mancha. Texto, introducción y notas de Martín de Riquer, Barcelona.

Rodríguez Marín, F. (1948), Miguel de Cervantes Saavedra, El ingenioso hidalgo Don Quijote de la Mancha. Nueva edición crítica con el comento refundido y mejorado y más de mil notas nuevas dispuesta por F. Rodríguez Marín, vol. 8, Madrid.

Schevill, R. - Bonilla, A. (1941), Miguel de Cervantes Saavedra, Don Quixote de la Mancha. Segunda parte; edición publicada por Rodolfo Schevill y Adolfo Bonilla, vol. 4. Madrid.

Sevilla, F. (2014), Miguel de Cervantes, Don Quijote de la Mancha. Edición de F. Sevilla. Introducción de A. Rey. 2 vols., Madrid (tercera edición).

Sevilla, F. - Rey Hazas, A. (1993), Miguel de Cervantes, Don Quijote de la Mancha. Edición de F. Sevilla Arroyo y A. Rey Hazas. Vol. I de la Obra completa, Alcalá de Henares.

\subsection{Otros}

REAL ACADEMIA ESPAÑOLA: Banco de datos (CORDE) [en línea]. Corpus diacrónico del español. <http://www.rae.es> [21 de marzo de 2019].

\section{Estudios}

Alcina, J. F. (2005), «Horacio en latín en España (1492-1700)», Edad de Oro XXIV, 7-25.

Andino Sánchez, A. de P. (2008), Las fuentes grecolatinas en el Quijote. Tesis doctoral, Universidad de Granada.

Barnés Vázquez, A. (2009), «Yo he leído en Virgilio»: la tradición clásica en el Quijote. Prólogo de Jean Canavaggio, Vigo.

Beltrán, R. (2014), «La fábula del ratón de campo y el ratón de ciudad y el monólogo de Areúsa sobre la vida de las criadas», Celestinesca 38 (2014) 11-36.

Bowditch, P. L. (2001), Horace and the Gift Economy of Patronage, Berkeley - Los Angeles - London.

Braund, S. H. (1989), «City and Country in Roman Satire», en S. H. Braund (ed.), Satire and Society in Ancient Rome, Exeter, 23-47.

Cairns, F. (1975), «Horace, Epode 2, Tibullus 1.1 and Rhetorical Praise of the Countryside», Mus. Phil. Lond. 1, 79-91.

Cascón Dorado, A. (2003-2004), «El ratón de campo y el ratón de ciudad. Historia y sentido de una fábula», Anuari de filologia. Secció D, Studia Graeca et Latina 12, 87-105.

Chevalier, M. (1999), Cuento tradicional, cultura, literatura (siglos XVI-XIX), Salamanca.

Chiong Rivero, H. (2008), «Ínsula de buen gobierno: el palimpsesto guevariano en 'Las Constituciones del gran gobernador Sancho Panza», Bulletin of the Cervantes Society of America 28.1, 135-165.

Close, A. J. (1990), «Algunas reflexiones sobre la sátira en Cervantes», Nueva Revista de Filología Hispánica XXXVIII, 492-511.

Close, A. J. (2015), «Pensamiento, personalidad y cultura», en Rico (2015, I.LXVIII-LXIX).

Colahan, C. (2012), «Auristela y Cenotia, personalidades horacianas en el Persiles», Anales Cervantinos XLIV, 173-186.

Cristóbal López, V. (1980), Virgilio y la temática bucólica en la tradición clásica. Tesis doctoral, Universidad Complutense, Madrid. 
Cristóbal López, V. (1992), «Búsqueda de campo, hastío de ciudad: pasión antigua y contemporánea», en F. J. Gómez Espelosín, A. Guzmán Guerra, J. L. Gómez-Pantoja Fernández-Salguero (coords.), Aspectos modernos de la Antigüedad y su aprovechamiento didáctico, Madrid, 131-144.

Ferri, R. (1993), I dispiaceri di un epicureo. Uno studio sulla poetica oraziana delle Epistole (con un capitolo su Persio), Pisa.

Finello, D. (1994), Pastoral Themes and Forms in Cervantes'fiction, London and Toronto.

Gómez Montoro, G. (2010), «El Show de Truman desde la perspectiva de la literatura y la teoría de la información y comunicación», Revista electrónica de estudios filológicos, XIX (julio de 2010) https:// www.um.es/tonosdigital/znum19/secciones/estudios-12truman.htm.

Güntert, G. (1994), «Lectura discursiva del Quijote, Primera y Segunda parte», en K. Reichenberger (ed.), Cervantes: Estudios en la víspera de su centenario, Kassel, 153-154.

Gutiérrez, M. A. (2009), Ael. Antonii Nebrissensis Gram. opera. Libri minores. Introducción, edición crítica y traducción de M. A. Gutiérrez, Salamanca.

Harrison, S. (2007), «Town and Country», en S. Harrison (ed.), The Cambridge Companion to Horace, Cambridge, 235-247.

Hayward, A. (1986), «On measuring an Horatian epistle (1.7)», $C W$ 80.1, 15-23.

Hiltbrunner, O. (1960), «Volteius Mena. Interpretationen zu Hor. epist. 1,7», Gymnasium 67, 289-300.

Hirth, H.-J. (1985), Horaz, der Dichter der Briefe. Rus und urbs: die Valenz der Briefform am Beispiel der ersten Epistel an Maecenas, Hildesheim.

Horsfall, N. (1993), La villa sabina di Orazio: il galateo della gratitudine. Una rilettura della settima epistola del libro primo, Venosa.

Jenkyns, R. (2013), God, Space, City in the Roman Imagination, Oxford.

Johnson, W. R. (1993), Horace and the Dialectic of Freedom. Readings on Epistles 1, Ithaca.

López Férez, J. A. (2005), «Datos sobre la tradición clásica en el Quijote», Fortunatae 16, 151-162.

López Férez, J. A. (2008), «Datos sobre la tradición clásica en el "Quijote”», en Felipe B. Pedraza Jiménez y Rafael González Cañal (eds.), Con los pies en la tierra. Don Quijote en su marco geográfico e histórico: XII Coloquio Internacional de la Asociación de Cervantistas, Cuenca, 491-508 (= López Férez 2005).

López-Cañete Quiles, D. (2015), «El tiempo devorador, el tiempo descubridor: dos notas sobre tradición clásica en Cervantes», Calamus renascens 16, 103-125.

López-Cañete Quiles, D. (en prensa), «Horacio y el Quijote, II 43», en J. M. Maestre et alii (coords.), Humanismo y pervivencia del mundo clásico, $V$. Homenaje al profesor Eustaquio Sánchez Salor, Alcañiz - Madrid.

Marasso, A. (1954), Cervantes: la invención del Quijote, Buenos Aires.

Marías Martínez, C. (2016), «La recepción de Horacio en el Siglo de Oro: traducciones en prosa y verso y estudio del caso de "Nil admirari" (Ep. I, 6)», Camenae 18, 1-24.

Mayer, R. (1994), Horace. Epistles I. Ed. by R. Mayer, Cambridge.

McCarter, S. (2015), Horace between Freedom and Slavery. The First Book of Epistles, Madison.

McGann, M. J. (1969), Studies in Horaces's First Book of Epistles, Bruxelles.

Menéndez y Pelayo, M. (1952), Bibliografía Hispano-Latina Clásica, VI. Horacio, Madrid (reimpr. de Horacio en España I, Madrid, 1877).

Miralles Maldonado, J. C. (1997), «Lucilio y Horacio: El motivo del ornatus corporis en la sátira», QUCC 57.3, 119-138. 
Münzer, F. (1930), «L. Marcius Philippus», Paulys Real-Encyclopädie der Altertumswissenschaft, XIV, 2, 1562-1568.

Navarro Antolín, F. (2006), «Cervantes y la tradición clásica», en Asociación de Profesores de Español «Francisco Quevedo» (ed.), 4 siglos os contemplan: Cervantes y el Quijote, Madrid, 149-186.

Oliensis, E. (1998), Horace and the Rhetoric of Authority, Cambridge.

Otto, A. (1890), Die Sprichwörter der Römer, Leipzig.

Pelorson, J. M. (2015), «Lecturas del 'Quijote'», en Rico (2015, II 241-243).

Powell, J. G. F. (2005), «Cicero's Adaptation of Legal Latin in the De Legibus», en T. Reinhardt, J. N. Adams, and M. Lapidge (eds.), Aspects of the Language of Latin Prose, Oxford, 117-150.

Redondo, A. (1997), «Tradición carnavalesca y creación literaria. Del personaje de Sancho Panza al episodio de la Ínsula Barataria en el Quijote», en A. Redondo, Otra manera de leer el Quijote (Madrid 1997) 191-203 y 453-473 [= Bulletin Hispanique LXXX (1978) 39-70].

Santos, A. (2008), Barataria, la imaginada: el ideal utópico de don Quijote y Sancho, Santander.

Schwarz, L. (2013), «Horacio: Poética y poesía en la obra de Cervantes», en J. D. Vila (coord.), El Quijote desde su contexto cultural, Buenos Aires, 99-125.

Stegen, G. (1963), L'unité et la clarté des Épîtres d'Horace. Namur.

West, D. (1974), «Of Mice and Men: Horace, Satires 2.6.77-117», en A. J. Woodman and D. West (eds.) Quality and Pleasure in Latin Poetry, Cambridge, 67-80. 